\title{
CORRESPONDENCE
}

\section{SMALL FLAP SCLEROTOMY}

\section{To the Editor of THE BRITISH JOURNAL OF OpHTHALMOLOgy.}

SIR,-It is impossible briefly, and at the same time adequately, to answer Colonel Elliot's criticisms in the January issue of the Journal, of my paper published in December, 1920. But my reply will be direct and to the point, as we are agreed that truth is best served by plain speaking.

Colonel Elliot rejects true filtration through spongy cicatricial tissue as opposed to everything we know of the behaviour of scar tissue. What do we know histologically of the healing of eye wounds bathed in aqueous? Not very much as yet. "Indisputable anatomical material" to demonstrate true filtration is not likely to be obtained except by some rare chance, from an operation not very generally practised. Fortunately, it does not appear to.be very necessary (see below).

There follows a remark questioning the existence of drainage through the wound of which a section was shown in my paper. Colonel Elliot's criticism is that the description "would deceive no one but a tyro." The statement that there was a quite good area of oedematous conjunctiva over the wound was given in inverted commas to show that it was supplied by the able pathologist who kindly gave me the section. Coupled with the clinical appearances now well established in perfectly successful small flap sclerotomies, the definite conjunctival oedema over one of these sclerotomy wounds, which is seen to be gaping well and filled with loose tissue, must be taken nowadays as demonstrating conclusively true filtration. In this case the drainage was insufficient to counterbalance complete obliteration of the filtration angle of the eye; otherwise the specimen would not have become available. Though the drainage was almost certainly merely temporary, this temporary filtration seems to me to give in all probability a very fair representation of permanent true filtration. Anyone is at liberty to reject this opinion, but not, I consider, to deny the existence of filtration in this case at the time.

Of sclero-corneal scars that are hidden under opaque swollen conjunctiva, naturally no one can affirm anything absolute, though there is good reason to believe that this grade of conjunctival oedema always predicates an underlying fistula. But it is quite a mistake to argue from these invisible scars, as Elliot does, that "it is not possible to say from the mere inspection of a scar that it is not fistulous." This mistake is an example that the trouble that 
may arise from unnecessary confusion between the sclero-corneal scar and the secondary conjunctival changes over it. This confusion is commonly made in talking loosely of "bleby" or "vesicular" cicatrices, but without leading to trouble, since the underlying scars are then more or less visible. Truly filtering cicatrices are generally so clearly visible through the nearly normal conjunctiva, that one is able to examine them minutely without the least trouble.

Much misconception would have been avoided if more time and trouble had been expended on methodical careful examination of the results of glaucoma operations, with focal illumination and a +20 lens. I am firmly of opinion that such clinical inspection alone of the typical cicatrix of small flap sclerotomy is sufficient to convince an unprejudiced observer of the reality of true filtration. The perfectly uniform grey tissue is there clearly to be seen in the scar lines, which vary only in width, being often broadest at the end of the flap. Seeing this, one could not possibly accept Colonel Elliot's supposition that when "a mere sclerotomy provides a permanent filtering scar," it does so by complete absence of healing. Elliot clings to the idea of all or nothing in this matter. Nature does not work on these hard and fast lines; it is rather a question of degrees, more or less. One cannot apply the observation of the cut iris remaining unhealed, unreservedly to wounds in the cornea and sclera. For instance, in some trephine holes there may certainly be partial healing, just as there may in other cases be complete healing. The last two trephined eyes which I have seen (in one patient) exemplify this. The scleral openings had become filled or covered by white fibrous tissue, not smooth and even, but apparently in coarse strands. Drainage was shown by well-marked widespread oedema, and by a little localized, partly transparent, elevation over the trephine spots. Plus tension had returned six years after operation, unmistakably in one eye and less markedly in the fellow eye. I do not suppose that any recent change had taken place in the scars; presumably the leakage was no longer sufficient to counterbalance advancing glaucomatous changes in the eyes.

To Coloriel Elliot "the presence of this connective tissue in a wound is an indication that that wound is no longer absolutely aseptic." I am sure that this suggestion will find no support in the experience of the vast majority of eye surgeons. Applied to my own work, it would mean that all my best results for many years had been obtained through mild infection.

To Colonel Elliot I seem to have attempted to make facts fit in with preconceived theory. To my mind there has been nothing in my glaucoma work but patient and laboured clinical observations continued over many years, together with some simple deduction and attempts at practical application. 
I am not wholly an "antagonist of sclerectomy," and have at times been glad to switch on to some form of it. For instance, it may be a simple matter to excise the posterior lip of a keratome incision, fixed by fine forceps; the cutting from without inwards can readily be done by sawing , with a Graefe knife. I have seen most admirable filtering cicatrices from Lagrange's operation. But it is otherwise with trephining.

In the prevention of late infection through iris-free leaking scars, our aims may be summarized as follows :

(A) One of the chief aims is to promote wide diffusion of aqueous under the conjunctiva. This may be attained (1) by a sclerocorneal wound which reaches the scleral surface at a little distance behind the conjunctival limbus, where the conjunctiva is thick and loose. Also (2) by extending the wound in a line parallel to the corneal margin. And (3) by the avoidance of adherent conjunctival scars.

(B) Apparently of equal importance is restriction of the flow of aqueous by limitation of the size of the sclero-corneal opening. In the milder glaucomas particularly, in which true filtration has been found fully effective, restriction of the flow of aqueous may be obtained also by securing this form of leakage, rather than drainage through a definitely fistulous opening. This is secured by making the sclero-corneal wound narrow, the required leaking area being got by length rather than breadth.

(C) By true filtration also we may hope directly to prevent deep penetration of surface organisms, the latter being held in the spongy tissue.

The very antithesis of A (1) and (2) is reached in a round hole beneath the thin adherent limbus. And apparently some trephine holes may be thus described, and therefore held in these respects to be the worst possible form of sclerectomy, entailing the maximum risk of infection.

Never having seen any of Colonel Elliot's results, I am at a disadvantage in commenting on his work, but his clear descriptions seem to afford ground for the following remarks.

He has undoubtedly improved matters greatly by the well-known splitting of the cornea. A conjunctivo-corneal flap is raised, consisting purely of the superficial corneal layers at its base. Since the splitting of the cornea is begun as far back as possible, after the definition of the conjunctival limbus (see pages 453 and 455 of Elliot's Text-book), we may conclude that a thin layer of corneal tissue is commonly included immediately beneath the limbus, strengthening it.

If the cornea is split as far as $1.75 \mathrm{~mm}$. from its margin, and full advantage is taken of this corneal reflexion in applying a $2 \mathrm{~mm}$. trephine, it seems obvious that half or more of the trephine hole 
must be afterwards covered by the corneal tissue thus included in the conjunctivo-corneal flap. (I do not understand Colonel Elliot's bewilderment over my reference to this matter.) (What becomes of this corneal covering? I suggest that little or no aqueous filters through this comparatively firm tissue, and that the fluid passes forward mainly or entirely through the part (half or less) of the trephine hole which is covered only by conjunctiva. If this is so, the passage for fluid is narrowed to a semi-circle or less, i.e., a gap with a maximum length of $2 \mathrm{~mm}$. and maximum breadth of $1 \mathrm{~mm}$., situated immediately behind the conjunctival limbus. And I suggest that this fact may account largely for the superiority of Elliot's own results, as compared with those of some other trephiners, and with those got by Holth's punch operation. But obviously such an opening falls far short of the possibilities under A (1) and (2). By other means one can easily make a decidedly longer opening, and place it further away from the corneal margin.

I do not know if any eyes have been removed after trephining in which full advantage has been taken of extensive splitting of the cornea. It would be interesting to note the changes in the corneal layers which formed part of the corneo-conjunctival flap.

Elliot's sole or main object in splitting the cornea appears to be the placing of the trephine opening well away from the ciliary body. For the prevention of late infection he lays particular emphasis on the inclusion of all the sub-conjunctival tissue in his flap. But both conjunctiva and sub-conjunctival tissue are sometimes very thin near the limbus. In my own practice I well remember producing one of the worst possible blebs in a case where the conjunctiva and sub-conjunctival tissue had not been disturbed at all over the sclero-corneal opening. The latter had resulted from the stretching with forceps of a small puncture, made by a bent broad needle after sliding the conjunctiva.

A circular sclero-corneal opening being of all wounds the one tending most to fistulization, as opposed to true filtration, it is necessarily the worst possible form of wound as regards the aim (C) above.

I have never regarded small flap sclerotomy as ideal; it fails too often to give the desired result in severe advanced glaucoma, as I found in India. Yet in many of the primary glaucomas of this country it gives a quite ideal result, safe and lasting. For these particular cases, therefore, it may be accepted as a perfect method. And there seems every reason to define and to enlarge, as far as possible, the group of glaucomas in which it serves best. I feel sure there are ways not touched upon in my recent paper, of rendering the result of the operation more certain.

It was largely, but not wholly, on personal experience that my statement was based, regarding the indifferent success which seems 
to have rewarded our attempts to graduate leakage in accordance with the needs of the case. I readily believe that the dangerous conjunctival blebs with hypotony, which betoken excessive leakage, may have been rare in Colonel Elliot's hands. Yet he has insisted both at the last Oxford Congress and again now, that some risk of infection must be accepted as inevitable with all the modern successful glaucoma operations. I would certainly agree with this opinion if we had no resource but iris-free fistulization. It seems fairly well established that in many of the severer chronic glaucomas the flow of aqueous needed for full relief of tension is so great that it cannot be obtained by iris-free drainage without risk, sometimes perhaps considerable risk.

In conclusion, it is well to bear in mind that only one of the two chief defects of drainage by fistulization has been discussed above. The value of this form of drainage must depend very largely on the question of the permanence of relief of tension provided by the smaller fistulae, yet to be decided.

I hope to bring up the question of the treatment of glaucoma by iris-prolapse at the Ophthalmological Society's Congress in May.

Yours truly,

H. HERBERT, Lt.-Colonel, I.M.S.

\section{A SCHOOL OF OPHTHALMOLOGY FOR LONDON}

\section{To the Editor of The British Journal of Ophthalmology}

SIR,-I must confess to a feeling of disappointment that the admirable suggestion made by Mr. M. S. Mayou in the February number of the Journal has not met with the open endorsement of readers. He practically proposes to amalgamate and to co-ordinate "The principal leading schools attached to the ophthalmic hospitals in London" for teaching purposes. I write in cordial agreement with Mr. Mayou. When I first came to London, tolerably acquainted with clinical and operative eye work, I hastened to attach myself to one of the ophthalmic hospitals, not one of the least well reputed. The teaching based on actual clinical material could not well be beaten, but when I began to look about for tuition in pathology I found that although a gentleman bore the title of "pathologist" to the institution, I had never seen him, and though well acquainted with the hospital premises, failed utterly to locate his habitat. As a result I was compelled to seek pathological instruction elsewhere. Again, as to optics, no attempt was made at the hospital in question to instruct students in what I knew to be from my text books an important subject. Accordingly, I was driven to attend 